\title{
On the rise but still underutilized - why statins are the Achilles' heel of secondary prevention in peripheral arterial disease
}

\author{
Christian-Alexander Behrendt and Frederik Peters \\ Department of Vascular Medicine, Research Group GermanVasc, University Heart and Vascular Center Hamburg, \\ University Medical Center Hamburg-Eppendorf, Hamburg, Germany
}

In a large-scale retrospective analysis of health insurance claims from Germany, we recently aimed to illuminate the post-discharge pharmacological treatment of patients hospitalized for symptomatic peripheral arterial disease (PAD). Among this well defined cohort of 83,867 patients (mean age $72 y, 46 \%$ women, $54 \%$ intermittent claudication), during the first half year after discharge only $37 \%$ of women and $43 \%$ of men received an optimal pharmacological treatment including lipid-lowering drugs, antithrombotics, and antihypertensives. Thereby, drug utilization differed considerably between those three groups. While in 2018 close to $90 \%$ of the patients were on antihypertensives and almost $80 \%$ on antithrombotics, as few as $58 \%$ of women and $66 \%$ of men received statins after being discharged from a hospital [1]. In 2010, statin utilization was even lower at $45 \%$ in women and $53 \%$ in men. Consequently, despite increasing prevalence efficient lipid management represents clearly the Achilles' heel of secondary prevention in symptomatic PAD. These findings for a German cohort are in line with striking results from an international meta-analysis on 19 studies and 26,985 patients, where only half of all patients with critical limb ischaemia received lipid-lowering drugs [2].

Interestingly, even among those treated with lipidlowering drugs the situation is far from satisfying. A global survey on the undertreatment of hypercholesterolaemia in 29 countries revealed that among 12,319 patients in Western Europe, only $57 \%$ attained their individual LDL-C goal. In Eastern Europe, even only 26\% in Eastern Europe attained their LDL-C goal, emphasizing a serious health care problem in a region covering $20 \%$ of the European inhabitants [3].

A beneficial impact of statins on the long-term outcomes after invasive treatment of patients with peripheral vascular disease has been demonstrated in previous studies. Statins reduced the incidence of major adverse limb events (MALE) by $30 \%$, amputations by $35 \%$, and all-cause mortality in patients by $39 \%[4,5]$. These clear benefits, and the fact that valid societal guidelines recommend their use based on high-level evidence [6-9] make it hard to believe that still more than 30\% remain untreated in a modern Western European healthcare system striving for providing optimal care universally. In 2018, Germany reported the fourth highest number of doctors consultations, and the highest health spendings and hospital discharge rates among European countries. The nationwide pharmaceutical expenditures increased by $5.4 \%$ to overall 43.4 billion euros in 2019, while $10 \%$ of this increase were attributable to antithrombotics [10]. Although statins generally remain one of the most commonly prescribed drug their burden for public healthcare budgets is comparatively low, given the availability of cheap generic options.

If not for budgetary reasons, what keeps general practitioners from prescribing statins, and what keeps patients from having their medical prescription filled? The answer to that question is likely multifactorial. While research on antithrombotics may be prone to a bias since over the counter medications are not always validly covered in administrative data, the situation is different for lipid-lowering drugs and statins. An increasing number of more than 2,500 million daily drug doses have been prescribed in Germany in 2019 (predominantly atorvastatin) [10]. Although rare, the risk of a statin-associated myopathy or increased risk to develop diabetes is often discussed against that backdrop. However, although minor muscle pain without laboratory changes was reported in up to $20 \%$, a severe adverse event was reported in less than 1 out of 1000 patients using statins [11]. Do practitioners simply believe that the benefit-to-harm ratio of statin therapy is less favorable in their patients currently untreated and therefore hesitate to issue a prescription for them?

To determine the efficacy and safety of initiating a statin therapy in previously untreated patients, we used longitudinal data on 22,208 patients with index revascularisation of either intermittent claudication or critical limb ischaemia. Also for this subgroup of statin-naïve patients, utilization 
rates considerably increased over time. While the longterm benefits clearly confirmed previous studies (hazard ratio between 0.75 and 0.80 for five-year all-cause mortality), there was no evidence for an increased incident diabetes or myopathy in those patients even if milder outpatient diagnoses were included [12]. In further analyses, the number needed to treat to prevent one death within 5 years was only 11 (for CLI) and 30 (for IC), respectively.

In light of these heartening results from large-scale and unselected real-world data, how can the multidisciplinary vascular community together achieve a substantial improvement in optimal pharmacological treatment of PAD? In contrast to other important pillars of medical therapy, we are not discussing comparatively small benefits vs. significant harms but $30 \%$ lower major event rates vs. a suspected $1 \%$ myopathy incidence.

Although guideline recommendations to prescribe statins independently from laboratory testings in symptomatic PAD patients are based on high-level evidence, very few studies address underlying reasons for the insufficient prescription rates such as the complex interaction and communication between patients and physicians [13]. Another important aspect is concerning the impact of a multidisciplinary approach on secondary medical prevention. Indeed, there is evidence that prescription rates may differ between medical specialties, and that multidisciplinary team decision in PAD treatment are rare and decreasing $[14,15]$.

In an ongoing VASCUNET and ICVR report on optimal pharmacological treatment, this cross-border collaboration aims to illuminate international variation and evidence for an East/West health divide in Europe to generate further hypotheses.

Undoubtably, more research is urgently needed to address this missed opportunity covering several millions of patients in Europe and worldwide.

\section{References}

1. Peters F, Kreutzburg T, Rieß HC, Heidemann F, Marschall U, LHoest $\mathrm{H}$, et al. Editors Choice - Optimal pharmacological treatment of symptomatic peripheral arterial occlusive disease and evidence of female patient disadvantage: An analysis of health insurance claims data. Eur J Vasc Endovasc Surg. 2020;60:421-9.

2. Kokkinidis DG, Arfaras-Melainis A, Giannopoulos S. Statin therapy for reduction of cardiovascular and limb-related events in critical limb ischemia: A systematic review and meta-analysis. Vasc Med. 2020;25:106-17.

3. Chiang C, Ferrières J, Gotcheva NN, Raal FJ, Shehab A, Sung J, et al. Suboptimal control of lipid levels: Results from 29 Countries Participating in the Centralized Pan-Regional Surveys on the Undertreatment of Hypercholesterolaemia (CEPHEUS). J Atheroscler Thromb. 2016;23:567-87.
4. De Martino RR, Eldrup-Jorgensen J, Nolan BW, Stone DH, Adams J, Bertges DJ, et al. Perioperative management with antiplatelet and statin medication is associated with reduced mortality following vascular surgery. J Vasc Surg. 2014;59: 1615-21.

5. Pastori D, Farcomeni A, Milanese A, Del Sole F, Menichelli D, Hiatt WR, et al. Statins and major adverse limb events in patients with peripheral artery disease: A systematic review and meta-analysis. Thromb Haemost. 2020;120:866-75.

6. Conte MS, Bradbury AW, Kolh P, White JV, Dick F, Fitridge R, et al. Global vascular guidelines on the management of chronic limb-threatening ischemia. Eur J Vasc Endovasc Surg. 2019;58:S1-S109.e33.

7. Gerhard-Herman MD, Gornik HL, Barrett C, Barshes NR, Corriere MA, Drachman DE, et al. 2016 AHA/ACC guideline on the management of patients with lower extremity peripheral artery disease: A report of the American College of Cardiology/ American Heart Association Task Force on Clinical Practice Guidelines. J Am Coll Cardiol. 2017;69:e71-e126.

8. Aboyans V, Ricco JB, Bartelink MEL, Bjorck M, Brodmann M, Cohntert T, et al. 2017 ESC Guidelines on the Diagnosis and Treatment of Peripheral Arterial Diseases, in collaboration with the European Society for Vascular Surgery (ESVS). Eur J Vasc Endovasc Surg. 2018;55:305-68.

9. Frank U, Nikol S, Belch J, Boc V, Brodmann M, Carpentier PH, et al. ESVM Guideline on peripheral arterial disease. VASA. 2019;48(Suppl 102):1-79.

10. Schwabe U, Ludwig WD. Arzneiverordnungs-Report 2000 2020. https://doi.org10.1007/978-3-662-62168-4

11. Stroes ES, Thompson PD, Corsini A, Vladutiu GD, Raal FJ, Ray KK, et al. Statin-associated muscle symptoms: impact on statin therapy-European Atherosclerosis Society Consensus Panel Statement on Assessment, Aetiology and Management. Eur Heart J. 2015;36:1012-22.

12. Peters F, Kuchenbecker J, Kreutzburg T, Marschall U, Debus ES, Behrendt CA. Long-term effectiveness and safety of initiating statin therapy after index revascularization in patients with peripheral arterial occlusive disease. J Am Heart Assoc. 2021;In Press. https://www.ahajournals.org/doi/full/ 10.1161/JAHA.120.018338

13. Corriere MA, Avise JA, Peterson LA, Stafford JM, Easterling D, Boone DS, et al. Exploring patient involvement in decision making for vascular procedures. J Vasc Surg. 2015;62:1032-9.

14. Klein-Weigel PF, Gutsche-Petrak B, Wolbergs S, Köning C, Flessenkamper I. Secondary medical prevention in patients with peripheral arterial disease - prescriptions of vascular surgeons and medical doctors (angiologists) in a multidisciplinary vascular centre. VASA. 2010;39:145-52.

15. Behrendt CA, Kölbel T, Schwaneberg T, Diener H, Hohnhold R, Debus ES, et al. Multidisciplinary team decision is rare and decreasing in percutaneous vascular interventions despite positive impact on inhospital outcomes. VASA. 2019;48:262-9.

\section{Correspondence address}

Priv.-Doz. Dr. med. Christian-Alexander Behrendt

Research Group GermanVasc

Department of Vascular Medicine

University Heart and Vascular Center Hamburg

University Medical Center Hamburg-Eppendorf

Hamburg

Germany

behrendt@hamburg.de 